\title{
12 The Karnak Project: A Comprehensive Edition of the Largest Ancient Egyptian Temple
}

\begin{abstract}
This article is concerned with the technical and methodological challenges encountered during a project to comprehensively document the inscriptions of the largest ancient Egyptian temple. This project aims to produce a complete inventory, and editing of, primary textual sources written in several varieties of the ancient Egyptian language and script: hieroglyphs, hieratic and demotic. The issues discussed concern the implementation of the digital tool, the need for a network of collaborators in order to process the large volume of documentation, and the need to identify digital solutions to preserve textual data from the Egyptian site. Finally, the lexicographic aspect of the project is discussed.
\end{abstract}

Keywords: ancient Egypt, Karnak temples, digital hieroglyphic corpora, high resolution orthophotographs, heritage preservation

\subsection{Introduction}

For nearly two millennia the temples of Karnak were one of the religious and political capitals of ancient Egypt. Today, they form an archaeological area of 25 hectares, where thousands of inscriptions, scenes and inscribed objects are preserved or have been discovered on-site. The temple consists of a main complex with a double eastwest and south-north axis (Figure 12.1) dedicated to the divinity Amun-Re who, among other prerogatives, guaranteed the rightful transmission of royalty. This complex has therefore received special attention from those who attempted to, or actually gained, power, each ruler seeking to leave his contribution in the temple of the "father" from whom he derived part of his legitimacy to govern. In addition, various temples dedicated to other deities, such as Ptah, Khonsu, and Osiris, are included in the main temple's enclosure. The hieroglyphic inscriptions of this complex range from 2000 BCE to the first century CE.

Despite the obvious historical, religious and linguistic importance of these documents, the publication of the lexical and iconographic data of this vast sanctuary was, until recently, far from complete. No compilation, index or glossary had been produced to extract the content of these documents.

Sébastien Biston-Moulin, CNRS, UMR 5140, Archéologie des sociétés méditerranéennes Christophe Thiers, CNRS, USR 3172, Centre Franco-Égyptien d’Étude des Temples de Karnak 


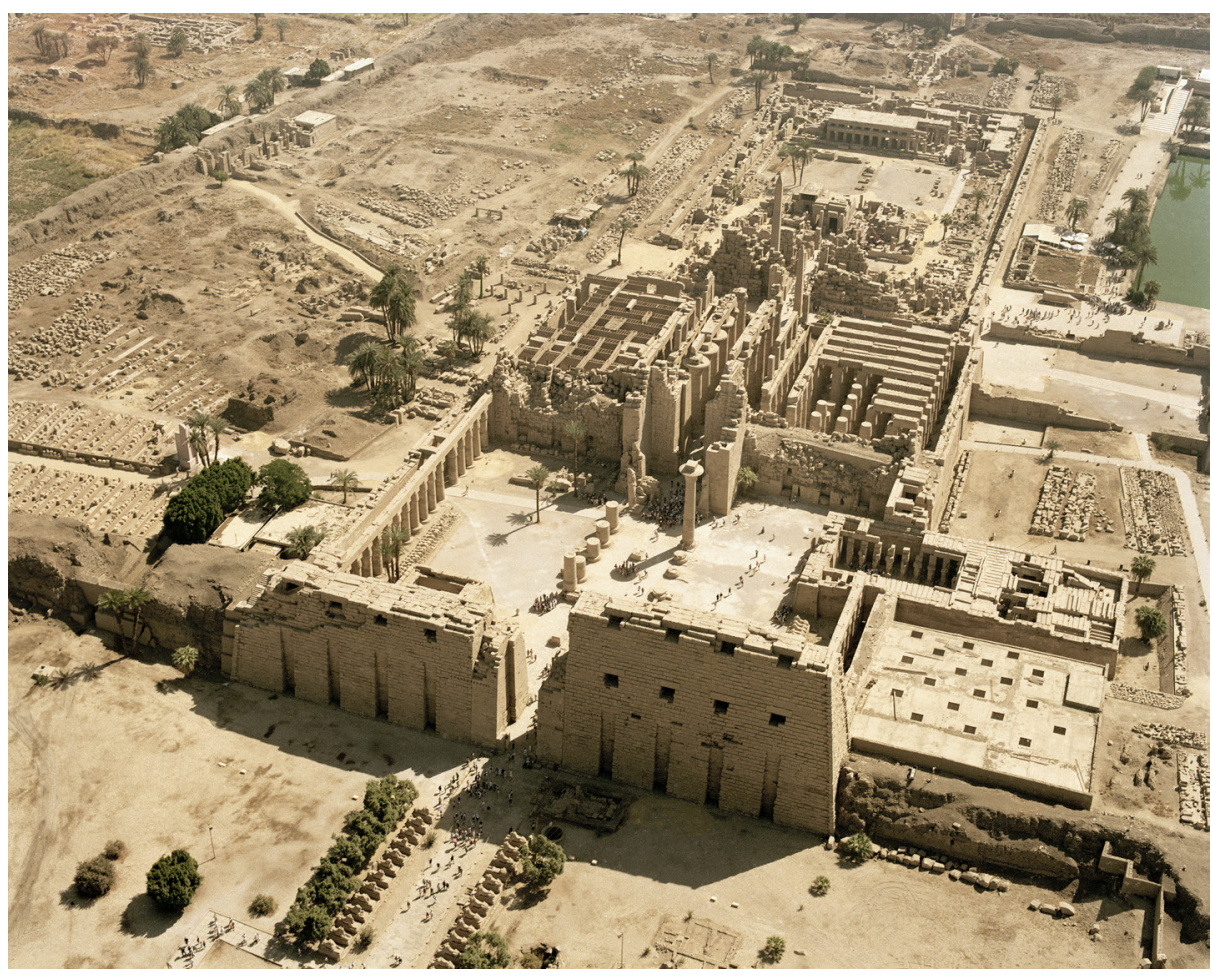

Figure 12.1: Main axis of the temple of Amun-Ra at Karnak (C CNRS-CFEETK)

Thanks to the presence of a permanent CNRS team on site, ${ }^{1}$ the objective of the Karnak project, initiated in 2013, was primarily to collect this unique amount of epigraphic material. This objective immediately raised the question of the organization of such documentation. How to collect, in an optimal way, these inscriptions that span millennia and use different writing systems, and subsequently, how to disseminate the richness of their contents as widely as possible? Since many of the inscriptions are still known only through hardcopies that are sometimes very old (mid-19 ${ }^{\text {th }}$ century), or remain unpublished, how to provide a level of documentation to be used both for the edition of primary sources and for research? Faced with a constantly deteriorating heritage, despite all the attention given to these monuments, what is the best way to sufficiently document, and thereby preserve, the information as it stands today, in the event of a deterioration of these reliefs?

To address these difficulties, we have chosen to build a comprehensive corpus of the primary sources from the site that would collect all the published and unpublished information concerning these inscriptions, as well as high-resolution photographs

1 French-Egyptian Centre for the Study of the Temples of Karnak (CFEETK - CNRS, USR 3172). 
serving autoptic reading. It was also necessary for this corpus to be georeferenced to set each inscription within its textual and iconographic context in the temple. Finally, in order to provide access to the content of the inscriptions, it was necessary to implement solutions for lexical analysis.

This corpus has obviously taken the form of a digital tool used both for editing hieroglyphic texts and for disseminating them.

\subsection{Towards an Interactive Corpus of Primary Sources in Ancient Egyptian}

\subsubsection{Fieldwork and Implementation of the Tools}

The first problem we faced was having a tool that could support the documentation related to a language (ancient Egyptian) that uses a figurative writing (hieroglyphs) with a set of signs having a potentially infinite number of graphic variants, without punctuation. The challenge was even wider, since a significant part of the Karnak temples' inscriptions (more than 10,000 in total) use further writing systems such as hieratic and demotic.

Since the 1990s, projects encoding hieroglyphic texts from a particular corpus or a language stage have multiplied, with the aim of producing lexicographic or morphological analysis tools. ${ }^{2}$ However, none of these tools was available for reuse and none seemed to be suitable for producing a reference edition of these texts. The sheer number of documents that needed to be processed was also an obstacle to overcome. It was therefore necessary to develop an ad hoc tool meeting the specific objectives of the project.

Hosted by the Huma-Num service grid, which aims to facilitate the digital turn in humanities and social sciences in France, this tool allows the project team to compile the corpus of the inscriptions of Karnak (Figure 12.2). ${ }^{3}$

Once the application had been implemented, the next problem encountered was the lack of an exhaustive inventory of the epigraphic documentation of the

2 To mention only the main ones: Thesaurus Linguae Aegyptiae (Hafemann \& Dils, 2013) [http:// aaew.bbaw.de/tla/] and Online Ramses (Polis, Honnay, \& Winand, 2013; Polis \& Winand, 2013) [http://ramses.ulg.ac.be/].

3 [http://sith.huma-num.fr/karnak]. 
Karnak complex. The project team ${ }^{4}$ proceeded to document the complex monument by monument, wall by wall, object by object. The process entails the cataloguing of scenes, objects and inscriptions in a common reference system and the creation of bibliographic records when they have already been published or mentioned. Every text receives a unique identification number (KIU: Karnak Identifiant Unique) that works as a reference throughout the project and enables the creation of URIs (Uniform Resource Identifier) for the inscriptions.

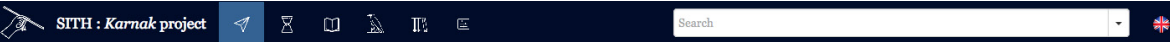

Apparition de la statue royale Scène 4 - (KIU 1098)

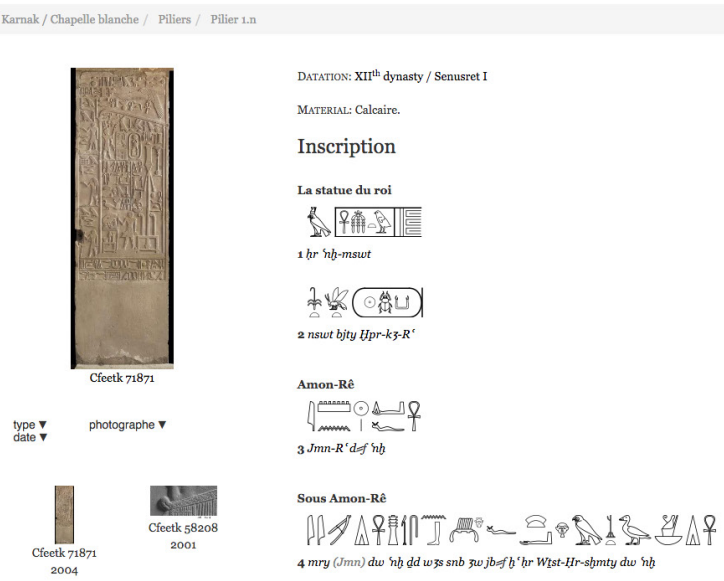

Figure 12.2: A scene and its inscriptions from the White Chapel of Senusret I (ca. 2000 BCE) ${ }^{5}$

The second issue was the integration of different language stages (Middle Egyptian, Late Egyptian, Ptolemaic) and writing systems (hieroglyphs, hieratic, demotic). Two teams, one from the University of Oxford (Dr. Elizabeth Frood and Chiara

4 Thanks to substantial funding in the form of a "Laboratoire d'Excellence" called Archimede, for a seven-year period (2013-2019), it has been possible to bring together a team that has grown over the years from five to seven people. Since 2013, 37 authors contributed to the project: Dr. Ali Abdelhalim Ali, Romane Betbeze, Silke Cassor-Pfeiffer, Dr. Léo Cagnard, Dr. Marion Claude, Dr. Laurent Coulon, Edwin Dalino, Dr. Gabriella Dembitz, Dr. Didier Devauchelle, Dr. Abraham Fernandez Pichel, Tiphaine Fignon, Elsa Fournie, Dr. Marc Gabolde, Dr. Luc Gabolde, Dr. Mohamed Gamal Rashed, Maeva Gervason, Mounir Habachy, Fanny Hamonic, Dr. Jérémy Hourdin, Marie-Paule Jung, Dr. Charlie Labarta, Dr. Françoise Labrique, Dr. Cédric Larcher, Mélie Louys, Dr. Dina Metawi, Dr. Elena Panaite, AnneHélène Perrot, Dr. Renaud Pietri, Dr. René Preys, Dr. Émeline Pulicani, Dr. Mohamed Raafat Abbas, Dr. Laurie Rouviere, Chiara Salvador, Dr. Anaïs Tillier, Dr. Ghislaine Widmer and the present authors. 5 [http://sith.huma-num.fr/karnak/1098]. 
Salvador) and the other from the University of Lille (Dr. Didier Devauchelle and Dr. Ghislaine Widmer), thus joined the project for the integration of hieratic and demotic documentation. While hieroglyphic texts are entered using a hieroglyphic word processor (Rosmorduc, 2014) and a font adapted to Karnak's inscriptions, we have chosen, in accordance with these two partners, to use facsimiles embedded in the interface as a medium for the hieratic and demotic texts.

All inventoried documents have been then organized topographically, and the decorations of the monuments have been arranged hierarchically by section, wall, register, and so on. This work enables immediate contextualization of the different texts in the temples, and the ability to move easily from one to those around it.

To avoid restricting the work carried out on the project's online interface, a first volume of the inventory of monuments, objects, scenes and inscriptions of the temples of Karnak, gathering all information collected in the framework of the project, was published in 2016 (Biston-Moulin, 2016). This inventory will be periodically updated in the coming years.

The project seeks to be as thorough as possible and includes data from the Cachette of Karnak, a database which has been developed by the French Institute for Oriental Archaeology (IFAO) and the CNRS since 2006 (Coulon \& Jambon, 2016) devoted to about a thousand statues and objects unearthed at the same location in the Karnak temple at the beginning of the $19^{\text {th }}$ century, and which are now kept in various museums around the world. ${ }^{6}$

\subsubsection{Production and Dissemination of Reference Documents}

An additional technical difficulty was managing a large amount of photographic data. In addition to the text edition, one of the objectives of the Karnak project is to produce a complete photographic record of the inscriptions of the temples. Highresolution photographs had to accompany the publication of the inscriptions in the project interface. We have chosen to transfer the management of these files to Nakala, a service also provided by the Huma-Num research infrastructure for raw data, ${ }^{7}$ which grants unlimited storage for this photographic coverage. These files are thus separated from the publication interface of hieroglyphic texts, but can be accessed at any time as a reference document. Facsimiles of inscriptions and other archival documents may also be made available in this way.

6 The database of the Cachette is available at [http://www.ifao.egnet.net/bases/cachette/]; for the implementation of its data in the Karnak project, see [http://sith.huma-num.fr/karnak/3312].

7 [https://www.nakala.fr/]. 
These high-resolution photographs are given metadata and distributed online. The metadata associated with these documents are interoperable (RDF/Sparql) to allow searches and ensure both data accessibility and reliability over time.

The user is therefore consistently provided with tools for source criticism. The photographs also allow access to the palaeography of texts and to the relationship between these and the decors. The whole collection of archival photographs of the CFEETK, which cover nearly 150 years of work in the temple (1870-2018), are also associated with the relative documents through the Nakala repository, showing whether a text or a decoration is in a different state of preservation or context than in the past. Approximately 30,000 photographs illustrating the inscriptions are available at this stage.

In order to obtain this coverage, a photographic campaign was established. Photogrammetric techniques are consistently used to produce reliable high-resolution orthophotographs of temple walls and objects in a limited time (Figure 12.3; Tournadre et al., 2017).

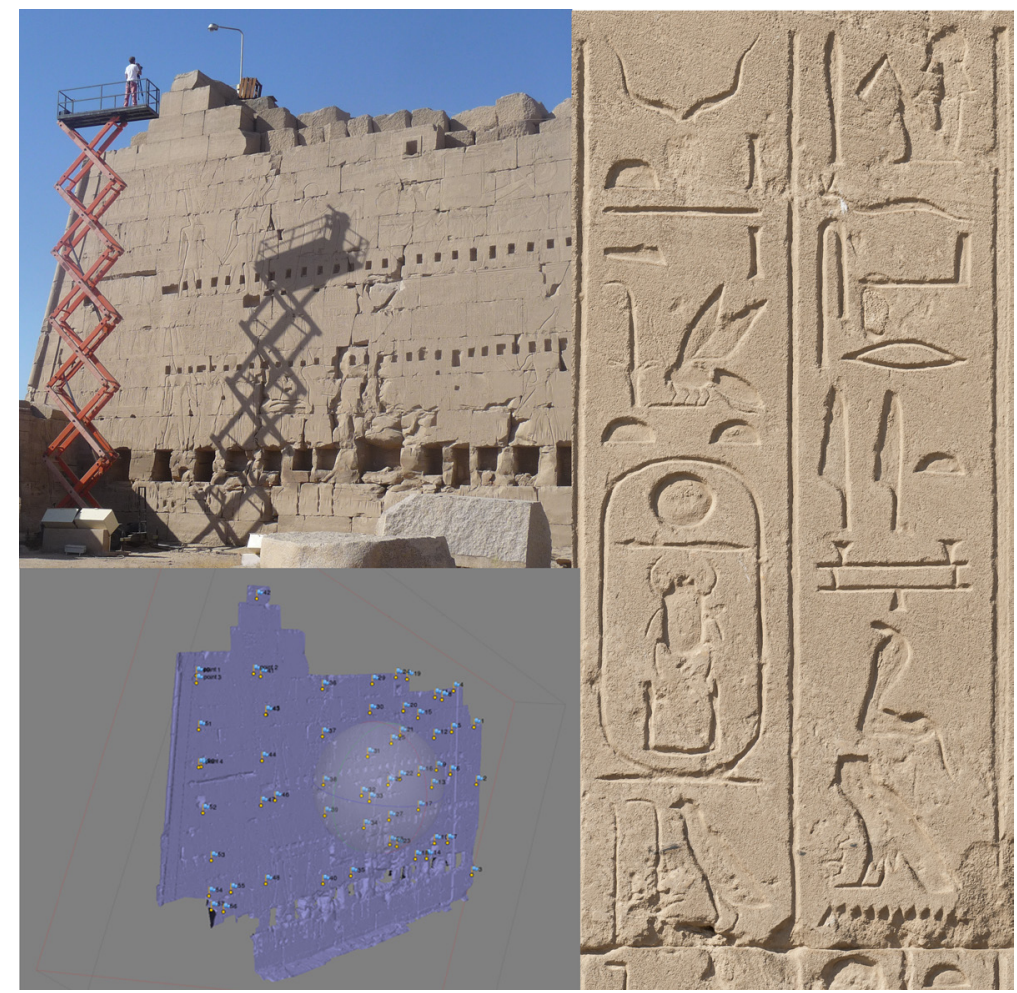

Figure 12.3: Orthophotographic survey, data processing in Photoscan and detail of orthophotography of an inscription several meters high acquired by means of this technique 
This exhaustive photographic coverage, the first made for Karnak, is also intended to preserve the textual and iconographic heritage of the temple as it stands today. Climate and anthropogenic degradations are to be feared and the disappearance of a relief, or part of it, is an irreplaceable loss. This may be counteracted with exploitable, high-resolution photographs, making this programme an absolutely crucial step towards the heritage preservation of the largest temple of Egypt, and should be encouraged on a broader level for all Egyptian sites. Although this method is very fast to implement and the work is progressing rapidly, one of our concerns is that it may be difficult to complete the photographic coverage within the timeframe of the project funding.

\subsubsection{From Plain Text to Indexed Interactive Text}

The last technical issue we will discuss here is linked to the encoding of texts in ancient Egyptian. An interactive text in which the user can search, browse and see the contents with indexes has always been one of the central ideas of the project. Because of the complexity of the corpus itself, and the priority given to the acquisition and publication of primary sources on site, this step of the project could not be undertaken before 2015. In order to achieve this objective for hieroglyphic inscriptions, it was necessary to develop an indexation system flexible enough to process a very large quantity of lexical data, but also sufficiently detailed to allow a careful lexical analysis of inscriptions.

Because of the partial knowledge of the ancient Egyptian vocabulary, we obviously needed a partner at this stage to undertake this lexical exploitation of Karnak's data. We turned to the dictionary project of the University of Montpellier VÉgA Vocabulaire de l'Égyptien Ancien led by Fr. Servajean, which aims to produce the first updated dictionary of ancient Egyptian in French since Jean-François Champollion. ${ }^{8}$ The richness of the data collected by the Karnak project was greatly valuable for the production of a dictionary, thus facilitating the partnership between the two projects.

In 2015 we were therefore able to develop a new tool called "Système d'Indexation des Textes Hiéroglyphiques”, for indexing hieroglyphic, hieratic and demotic texts. This programme is designed to create lists of words, theonyms, toponyms, ethnic names and cult places, anthroponyms and names of kings from the contents of the corpus. It then detects possible attestations and allows the creation of indexes, classified both chronologically and topographically in the temple. To date, thanks to the indexing work, several hundred thousand attestations of identified terms and contexts are proposed. This application is used to transform the plain text entered by the members of the project into an interactive text indexed by the detection of

8 [http://vega-vocabulaire-egyptien-ancien.fr/]. 
the occurrences and morphological features of the elements of the sentence. Each possible attestation is then manually validated or rejected. The result is an annotated corpus that allows very detailed searches or compilations based on chronology, grammatical features or context of use (Figure 12.4).
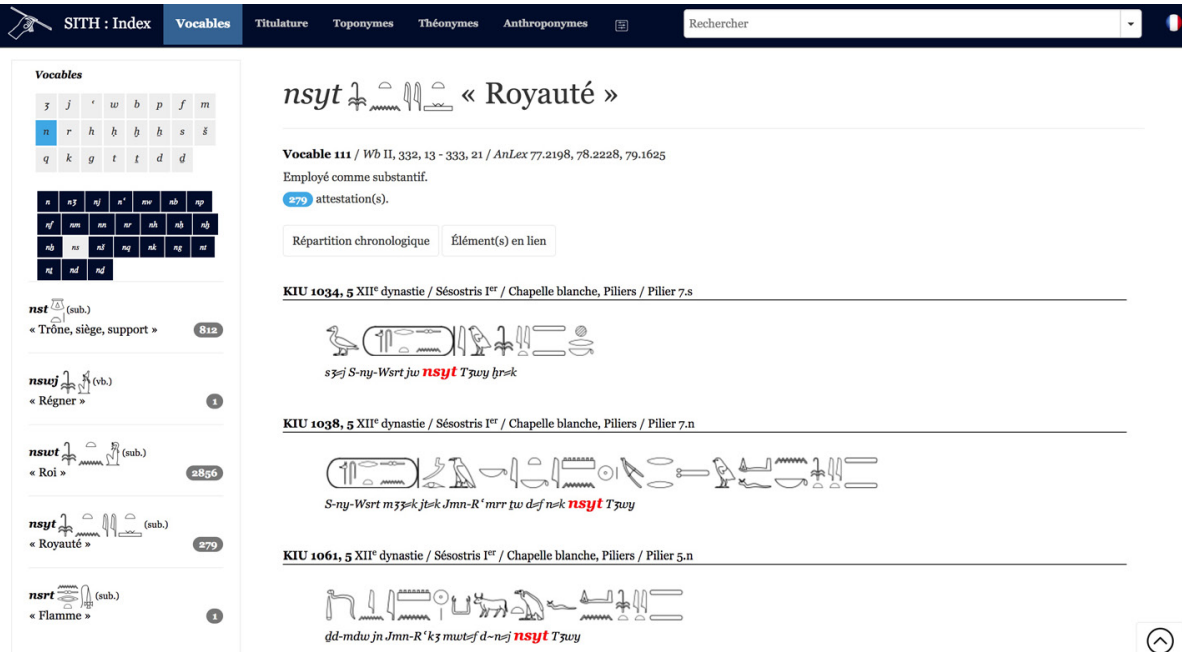

Figure 12.4: The world nsyt « Kingship » in the inscriptions of Karnak ${ }^{9}$

To broaden the dissemination of this compiled data, and reach a different audience from the online interface, a first volume of the Glossary of the Inscriptions of Karnak dedicated to the vocabulary was published in 2017 (Biston-Moulin, 2017). It includes about 100,000 word attestations spread over a little more than 2,000 years of use in Karnak. In the coming years, it is intended to periodically update this volume, giving access to an ever-increasing number of texts, and identified terms, attestations and contexts.

Much remains to be done in order to complete and enrich the indexation of the inscriptions collected as part of the constitution of the corpus of Karnak texts. One of the objectives will be to make the whole corpus fully interoperable (TEI/EpiDoc) in order to increase its dissemination and allow the total or partial reuse of Karnak texts and indexed lexical data.

One of the main difficulties in advancing this part of the project is the absence of a recent reference work or compilation mainly for lexicon, anthropoyms or toponyms. While the production of a lexicon of ancient Egyptian will hopefully be achieved

9 [http://sith.huma-num.fr/vocable/111]. 
as a result of the progress of projects dealing with dictionaries, the production of an updated geographical gazetteer of toponyms attested in Egyptian inscriptions remains a remarkable desideratum. ${ }^{10}$

\subsection{Progress and Prospects}

These are a few aspects of the main technical and methodological challenges that the Karnak project has had to overcome in the course of the production, still in progress, of the largest corpus of hieroglyphic texts freely available online.

Through the choices made at the outset of the project, then during its development, and the technical solutions developed along the way, five years after its launch the Karnak project has collected, organized and edited more than 10,000 hieroglyphic, hieratic and demotic inscriptions. Its online interface available in French, English and Arabic has received more than 4,000,000 visitors.

The edition of the Karnak project corpus will be completed in the coming years and our attention is now turning to the future of the data collected in the course of this digital epigraphy project. All the photographs are already stored and distributed via a system ensuring their long-term preservation. All of the textual data will be released in Open Access under a Creative Commons license. ${ }^{11}$

Beyond the difficulty in finding reference tools for ancient Egyptian, one of the unresolved questions of the project is the catalogue of the graphic variants of the hieroglyphic signs composing the various attestations of one term. This would be an extremely valuable addition to the existing data, but will probably require the implementation of specific tools that have yet to be defined for the project. This dimension obviously involves the photographic documentation that we have already collected, but also the work on the facsimiles. Even though this activity has been carried out since the beginning of the project, its progress is very slow, because of the time needed to produce such documents.

The technical solutions and methodological choices adopted in the development of a digital epigraphy project on the largest Egyptian temple could naturally function as a foundation for the extension of the project beyond the Karnak temples. Integrating texts from other Egyptian sites or thematic corpora would certainly be the right step

10 These geographical names obviously concern territories, cities, temples, and monuments all over Egypt, but they also include numerous Asian and African territories, localities and ethnics whose names have been recorded in Egyptian texts. A few references to European place names such as the name of the city of Rome $(\mathrm{Hrm})$ engraved in hieroglyphic inscriptions of Emperor Augustus in the temple of Opet at Karnak may also be found: [http://sith.huma-num.fr/toponyme/33], [https://www. nakala.fr/nakala/data/11280/e24901f5].

11 Attribution-ShareAlike 4.0 International (CC BY-SA 4.0) [https://creativecommons.org/licenses/by$\mathrm{sa} / 4.0 /]$. 
to open the way for a much larger collection of inscriptions in ancient Egyptian, overcoming the obstacles discussed here and benefiting from the flexibility and advantages of digital epigraphy for the edition, analysis and publication of sources in ancient Egyptian.

\section{Bibliography}

Biston-Moulin, S. (2016). Inventaire des monuments, objets, scènes et inscriptions des temples de Karnak. Montpellier. Retrieved from [https://halshs.archives-ouvertes.fr/halshs-01329927/ document], 2017/11/1.

Biston-Moulin, S. (2017). Glossaire des inscriptions de Karnak I. Le vocabulaire. Montpellier. Retrieved from [https://halshs.archives-ouvertes.fr/hal-01549230/document], 2017/11/1.

Coulon, L. \& Jambon, E. (2016). L'exploitation scientifique de la Cachette de Karnak, de Georges Legrain à nos jours. Essai d'historiographie. In L. Coulon (Ed.), La Cachette de Karnak. Nouvelles perspectives sur les découvertes de Georges Legrain (pp. 89-129). Cairo: Ifao.

Hafemann, I. \& Dils, P. (2013). Der Thesaurus Linguae Aegyptiae - Konzepte und Perspektiven. In I. Hafemann (Ed.), Perspektiven einer corpusbasierten historischen Linguistik und Philologie. Internationale Tagung des Akademienvorhabens „Altägyptisches Wörterbuch“ an der BerlinBrandenburgischen Akademie der Wissenschaften, 12.-13. Dezember 2011 (pp. 127-143). Berlin: BBAW.

Polis, S., Honnay, A.-C., \& Winand, J. (2013). Building an Annotated Corpus of Late Egyptian. The Ramses Project: Review and Perspectives. In S. Polis \& J. Winand (Eds.), Texts, Languages \& Information Technology in Egyptology (pp. 25-44). Liège: Presses universitaire.

Polis, S. \& Winand, J. (2013). The Ramses project. Methodology and practices in the annotation of Late Egyptian Texts. In I. Hafemann (Ed.), Perspektiven einer corpusbasierten historischen Linguistik und Philologie. Internationale Tagung des Akademienvorhabens „Altägyptisches Wörterbuch" an der Berlin-Brandenburgischen Akademie der Wissenschaften, 12. - 13. Dezember 2011 (pp. 81-108). Berlin: BBAW.

Rosmorduc, S. (2014). JSesh Documentation. Retrieved from [http://jseshdoc.qenherkhopeshef.org], 2017/11/17.

Tournadre, V., Labarta, Ch., Megard, P., Garric, A., Saubestre, E., \& Durand, B. (2017). Computer Vision in the Temples of Karnak: Past, Present \& Future. The International Archives of the Photogrammetry, Remote Sensing and Spatial Information Sciences, 42-5/W1, 357-364. doi: 10.5194/isprs-archives-XLII-5-W1-357-20 